\title{
Is there an optimal environment in which to learn clinical anatomy? One man's view
}

\author{
Ang Eng-Tat ${ }^{1^{*}}$, Peter Abrahams ${ }^{2}$, Seow Choon Sheong ${ }^{3}$, Mikael Hartman ${ }^{4,5}$ \\ ${ }^{1}$ Department of Anatomy, Yong Loo Lin School of Medicine, National University of Singapore, Singapore; \\ *Corresponding Author: eng_tat_ang@nuhs.edu.sg \\ ${ }^{2}$ Warwick Medical School, West Midlands Surgical Training Centre, Coventry CV4 7AL, UK \\ ${ }^{3}$ Department of Surgery, Alexandra Hospital, Jurong Health, Singapore \\ ${ }^{4}$ Department of Surgery, Yong Loo Lin School of Medicine, National University of Singapore, Singapore \\ ${ }^{5}$ NUS Saw Swee Hock School of Public Health, National University of Singapore, Singapore
}

Received 26 October 2013; revised 4 December 2013; accepted 16 December 2013

Copyright (C) 2014 Ang Eng-Tat et al. This is an open access article distributed under the Creative Commons Attribution License, which permits unrestricted use, distribution, and reproduction in any medium, provided the original work is properly cited. In accordance of the Creative Commons Attribution License all Copyrights (C) 2014 are reserved for SCIRP and the owner of the intellectual property Ang Eng-Tat et al. All Copyright (c) 2014 are guarded by law and by SCIRP as a guardian.

\section{ABSTRACT}

Learning anatomy is essential in medical schools, and even more so for budding surgeons. Much has been discussed regarding the updated curriculum, and whether the pedagogies should be based upon cadaveric, and/or multimedia, or hybrid approaches. Much debate has also been centered on who is best qualified to teach. While all these are important, the setting is also critically important for the medical students and surgical trainees. Therefore the overarching issue is whether all these activities should be held in the dissection room, the operating theatre or the classical "Theatrum Anatomicum"? What are the key experiential learning differences in picking up anatomical knowledge in the various venues listed above? This paper will provide some insights for teachers and students of human anatomy, and some ideas for the future planners and developers of anatomy learning centers internationally.

\section{KEYWORDS}

\section{Learning; Clinical Anatomy; Optimal Environment; Theatruman Atomicum; Dissection; Surgery}

\section{INTRODUCTION}

Traditionally, medical students have been learning human anatomy in a passive manner in the anatomical theatre where the professor lectured and barber surgeon demonstrated key structures in the cadaver [1]. This subsequently has changed due to more students and fewer tutors in place doing the teaching [2]. In brief, the anatomical education has been radically transformed worldwide [3,4]. Innovative practices include self-directed learning with resources for the students while the anatomy demonstrators roam around the lab clarifying doubts [5]. The above learning often takes place in the dissection room, a venue that has lost much of the aura that is used to instill diligence and respect [6]. Interestingly, there are now attempts to revive this learning atmosphere. Dubbed the "Theatrum Anatomicum" in one of the German universities, this allows the participants to behave as if they are in the operating theatre, to be observant and as sterile as possible, in a sense preparing them for their future surgical placements [1].

Currently, due to a lack of human bodies, attempts are made to keep the cadavers for as long as possible, which mean it is necessary to embalm the bodies. This creates the "smell" and the body in a state that is quite "unreal", given that the texture, feel and warm of the living skin are missing $[7,8]$. It is therefore not surprising that some students are put off as they do not even come for their dissection sessions at all. As some of these students will later on become physicians or psychiatrists, they wrongly perceive the subject matter to be of little concern to them. Understandably, physiology, pathology, pharmacology and biochemistry excite them more. However, the absence of a budding surgical trainee from the dissection hall is a matter of grave concern. With this question in mind, it is time to reassess if the venue for the teaching of anatomy is truly optimal.

Most clinical anatomists recommend that professional 
anatomists should work in close co-operation with their surgical colleagues so that the subject can be taught in a clinically relevant manner. Practicing surgeons understand troublesome issues and therefore are better positioned to teach medical students the anatomy for clinical practice. This is especially critical when it concerns minimal invasive procedures whereby all the anatomy that matters are seen through the monitor [9]. However the reality does not permit them to do so much teaching of anatomy as they have to worry more about patient's care, and workflow in the operating theatres. Therefore the issue is: how do we tap on these practitioner's insights and knowledge to distill their experiences and share them with the medical students? With these most relevant thoughts in mind, one of the authors (E.-T. Ang) decided to venture into "uncharted territories" away from the dissecting room, and lecture theatres, to become an "observer" in the operating theatre (OT).

In the name of learning anatomy, the followings were accounts of his observation of various surgical procedures:

1) Modified radical mastectomy with sentinel lymph nodes removal by Dr. Mikael Hartman.

2) Hernia repairs done via laparoscopic and open approaches by Dr. Seow Choon Sheong.

An attempt was then made to highlight the typical learning experience in the dissection room after each relevant section, so that readers can appreciate the stark learning differences taking place at the different venues.

\section{PROCEDURES IN THE PECTORAL REGION}

\subsection{Mastectomy}

Firstly, one had to scrub, gown and put on gloves in a sterile manner. This added to the sense of anticipation and the desire to observe what is to happen before one's eyes. After induction of anesthesia, the surgeon and his assistants injected methylene blue dye into the patient's diseased breast so that it will track into the lymphatic vessels which drain into the sentinel nodes [10]. The latter are the first lymph nodes that the lymphatic vessels will empty into and if found diseased, then metastasis would have already taken place and will change the treatment plan to include follow up with radiotherapy and/or chemotherapy. However, all these frozen samples are first viewed and verified by the pathologist.

Positions were taken up by the team and standard operating procedures necessitate all present to declare their identities before the commencement of the surgery. Markings were made on the breast to be operated upon; a reminder that surface anatomy is very important as there is no room for error. The incisions were made, and with the use of cautery the skin was dissected from the under- lying fascia, going deeper into the breast tissues. At this point, there is some bleeding, as the medial perforators from the internal thoracic (mammary) vessels are encountered, and these torn vessels had to be systematically cauterized, so as to allow the breast tissue to be separated from the underlying pectoral fascia. In summary, the arterial blood supply to the breast is as follows:

From the medial side of breast: mainly the internal thoracic (mammary) and from the lateral side of breast, branches of the lateral thoracoacromial and lateral thoracic arteries. The venous drainage of the breast is mainly into the internal thoracic vein, the axillary vein, and the vertebral plexus of veins via the segmental posterior intercostal route. The latter is clinically important as a possible route for metastatic spread to the spine in the absence of pulmonary metastases.

At this juncture, one has already learned much about surface anatomy, the skin, the underlying breast tissue, the retro-mammary space (bursa), and the underlying pectoralis major. All this is very intriguing for the observer, as he or she is now able to appreciate all these structures in a living person (patient) as opposed to the embalmed cadaver who tend to have atrophied breasts due to age and the preservation process.

Continuing on with the observation, the surgeon then proceeded to dissect out the sentinel lymph nodes that had been stained blue with the dye that were previously injected into the patient. The lymph nodes were examined and further dissected clean for the pathologist before sending them off to the laboratory for processing. In total, 2 - 3 lymph nodes from the apical clusters were removed for the pathologist to determine if the cancer in the breast had metastasized to the secondary lymph nodes [11]. Once again, the students can learn more about the anatomy of the lymphatic system draining the breast region, as any disruption may possibly result in lymphedema of the limbs although there are accompanying controversies [12-15].

The surgeon then separated the breast tissue away from the pectoral fascia, in a medial to lateral direction, causing some bleeding from the internal thoracic vessels. These blood vessels were either directly cauterized or indirectly via contact with the forceps. While removing the lymph nodes, one had to be careful not to injure the thoracodorsal branch of the scapular artery because if ruptured, the repair can be a tedious process. Breast tissue was then reflected off to show the gross surface of the underlying pectoralis major (PM) muscle. In this particular case, the tumor had not penetrated through the fascia into the underlying muscle, thereby giving good justification to spare the muscles beneath. Conversely, when there is penetration of the tumor into the muscle, then a radical mastectomy would have to be performed (it is actually rarely ever performed these days). After 
about an hour of dissection, the breast was adequately separated from the patient leaving only some contact between the breast tail with the axilla. It is known that the pectoralis major (PM) forms the anterior fold of the axilla, and is inserted onto the lateral lip of the intertubercular sulcus of the humerus. With the removal of the breast, the surgical team now has a clear view of the PM muscle that runs from the sternum and clavicle, and to the humerus of the upper limb, forming the anterior fold of the axilla. It is helpful to understand the action of the PM, as the patient's upper limb must be placed in an abducted position, as this would elongate the PM and allow the breast lying on its surface to become taut, thus allowing the surgeon better access to the tumor. One learnt a lot more about the human breast from this observation in the OT, compared to reading an anatomy textbook. However, here the challenge has always been the number of undergraduate students that could be accommodated in this type of learning.

\subsection{Cadaveric Dissection}

After removing the skin and fascia in the region, attention was given to the origin and insertion of the muscles namely pectoralis major and minor. One could also clearly see the medial and lateral pectoral nerves that innervate the above muscles. This is possible as one could afford an extensive incision and a big window for observation without endangering life per se, and the enormous blood loss if done on a living person. In the axilla, one could discern the lymph nodes in this region as well but not before the removal of enormous amount of fat and finding the blood vessels. In the cadaver, as there is no pulse and depending on the state of the body, tissues can be difficult to differentiate, such as nerves from blood vessels and vice versa. The immediate advantage over the experience in the OT is the possibility to make mistakes. There is also the issue of clarity, which was evidently missing in the OT, when one had to observe the procedure from a distance unless one was actively assisting the surgeon by retracting the skin and holding other instruments in place. Most importantly, one could explicitly appreciate the functions of muscles, the line of pull, and the location of the brachial plexus. Without any doubt, the big picture view of the brachial plexus, which includes the roots, trunks, division and cords in relation to the axillary artery, and the branches (Musculoskeletal, Median, Ulnar and Radial) were clearly observable. These structures cannot be readily appreciated in the OT.

\section{PROCEDURES IN THE ABDOMEN}

\subsection{Proceedings of Hernia Repair}

Two cases were observed-an extra-peritoneal lapa- roscopic approach view and an open groin hernia. Both offered different perspectives to the surgeon and trainees. The open view had a shorter learning curve due to its intuitive nature as explained by the surgeon. In laparoscopy, the landmark anatomy was the inferior epigastric artery (which also defines the lateral edge of the inguinal (Hesselbach's) triangle. One did not have to expose the lateral structures in this region, including the iliohypogastric and ilioinguinal nerves.

The first procedure was done with key-hole openings below the umbilicus, with two other ports placed between the umbilicus and the pubic tubercle. Observation of the inguinal (Hesselbach's) triangle was made extraperitoneally via a live monitor, with a view of the inferior epigastric vessels as the guide. The surgeon explained that this is the superior method as it poses less risk to the peritoneum [16]. The hernia sac was isolated and subsequently dissected out; a mesh was inserted to cover the weak area. Every effort is made to avoid the triangle of doom (the external iliac blood vessels) and the triangle of pain (iliohypogastric and ilio-inguinal, femoral nerves) as there are reported cases whereby neighboring nerves were injured [17]. Interestingly, the corona mortis was picked up in this procedure by the surgeon $[18,19]$. Learning anatomy in this manner was indeed difficult as the observer must first be oriented to the exact view shown on the monitor.

The second procedure was done via an open approach. The area was clearly marked out by the surgeon and this again reminded us all how important is surface anatomy. A small incision site was made through the skin, and the superficial fascia (Camper's \& Scarpa's). The three layers of abdominal muscles (external, internal and transversus muscles) and the transversalis fascia were encountered. The conjoint tendon, the arcuate line of pelvis (can be palpated on a living person), inferior epigastric vessels (IEV), the superficial and deep inguinal ring, and the spermatic cord were pointed out by the supervising surgeon. At this juncture, the observer should have learnt about the differences between direct versus indirect inguinal hernia (with reference to the IEV). The hernia sac was isolated (without disrupting the content) and then repaired using the mesh. The latter was anchored to the lateral edge of the rectus abdominis, and then to the inguinal ligament. Subsequently, all the above layers were sutured and skin closed. In this way, the anatomy was learned in a straightforward manner without much difficulty.

In summary, observations and tutorial made in the OT reinforced the fact that knowing the groin anatomy is crucial to the skillful expertise of the surgeon [20].

\subsection{Cadaveric Dissection}

As mentioned earlier, the immediate advantage in 
learning anatomy via this method was the opportunity to see the "Big picture" with no surgical drapes, or having to appreciate the structures through a small incision or looking at the video screen. Everything was open to dissection, with the possibility to retract structures out of the way to get a better view. The skin was removed, followed by the removal of superficial fatty (Camper) fascia before exposing the superficial membranous (Scarpa) fascia. The three layers of abdominal muscles, the conjoint tendon (contribution from the internal and transversus abdominis), the arcuate line below which the abdominal wall is deficient (all muscles now lie anterior to the rectus abdominis) leaving only the transversalis fascia were observed. The inferior epigastric vessels, branches from the external iliac vessels, were observed to be forming the lateral borders of the inguinal (Hesselbach's) triangle, before anastomosing with the superior epigastric vessels.

The deep and superficial rings were easily identified with the spermatic cord running between them, typically about $4 \mathrm{~cm}$ apart.

\section{LEARNING IN THE LECTURE THEATRE}

Learning anatomy in the lecture theatre is as follows. The lecturer outlines what would be discussed, and students are expected to follow what was presented via a system of slides, short video clips and some anecdotal clinical stories. A good lecturer can hold the student's attention if he or she is mindful of not overloading the student. However, this can be difficult due to a lack of proper resources such as good video clips from the dissection room and OT. To a certain extent some of these problems have been circumvented via the internet, as now one is able to harness the enormous amount of information from social media and YouTube. But a system like this could be quite difficult to achieve if there is no proper organization, or lack of internet connectivity as in many poorer parts of the world. Some of the advantages and disadvantages associated with learning anatomy in the lecture theatre are presented in Table 1.

\section{DISCUSSION}

The "tutorials, lectures and practical class" system of education is tightly linked to many institutions of higher learning since the earliest times. The lecturer will deliver the content to the largest number of students possible at a single time. Subsequently, any doubts the students may have will be mitigated during the tutorials and practical classes. The subject of anatomy is however rather peculiar, as it is often geared towards surgical applications for the doctor. As such, there may yet be room for some innovations. Concomitantly, modern students are abun- dantly good at multi-tasking; there is now evidence to suggest that small group teaching via highly interactive media might be the superior pedagogy. Pertaining to anatomy education whereby graphics and sounds are highly desirable, and taught in a clinical context, would it not be optimal for all three to be presented at the same time? Such an approach has been well described in instances whereby a hybrid system was utilized to teach medicine and surgery via the internet $[9,21]$. Concerted efforts of this scale can of course be very challenging, as the physical logistics matter, but these are not insurmountable as illustrated in numerous studies [22-25]. Importantly, these efforts will lead to better learning outcome for students [26].

There is also recent evidence to suggest that learning in a clinical context does help to improve motivation, inculcating "a deep approach" to the subject matter and better examination scores $[27,28]$. Specifically up to $72 \%$ of medical students in a recent survey reported improving their knowledge of anatomy while in the operating theatre (OT) [29]. Conversely, students that were showed dissection videos during lecture did not show any improved exam scores [30]. Being in the OT, also rightfully reminds the student to behave professionally in a sterile environment [1], and this becomes even more significant when they begin their surgical training.

Taken together, while the conventional way of teaching anatomy may be good, one should consider striving for better success at getting students to appreciate the subject better. One should aim to have hybridity in teaching anatomy so that students will understand from a surgical perspective. Online teaching might just be able to bridge many of the possibilities under the same roof for the medical students [31,32]. Recent evidence also suggests that such multi-disciplinary approaches were found to be very enriching (see Figure 1 and Table 1), especially for the surgical trainees [33].

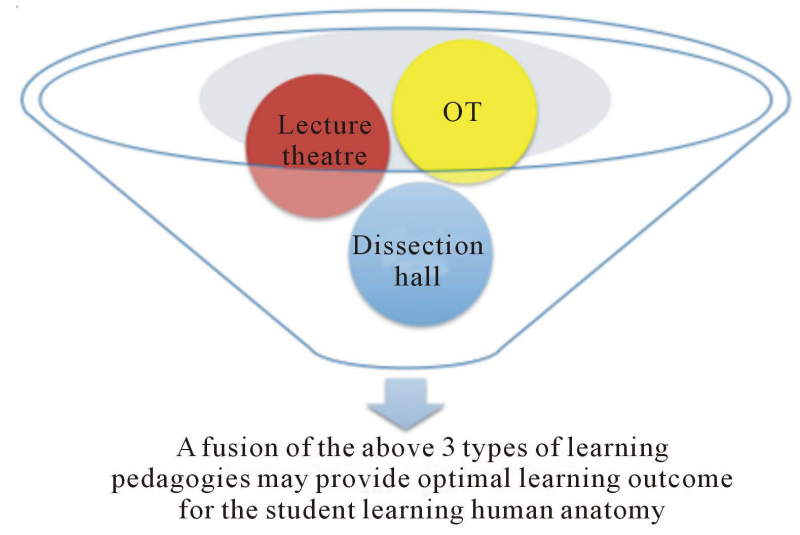

Figure 1. Proposed learning environment whereby inputs from the typical venues for learning human anatomy, namely the dissection room, the lecture theatre, and the operating theatre, could produce best outcome. 
Table 1. The advantages and disadvantages of anatomy learning experiences: in the dissection room, in the lecture theatre and in the operating theatre. In the dissection room and operating theatre, one does not see students falling asleep! In the lecture theatre, although a truly conducive environment, there are times when one learns better with some background noises (alarms of the pulse oximeter or life support system going off), or even activities that can keep you on the edge including the presence of a cadaver (to be respectful in the presence of the dead!).

\begin{tabular}{cc}
\hline Advantages & Disadvantages \\
\hline
\end{tabular}

\section{In the dissection room}

No confounding blood which will hinder observation of structures. Big picture anatomy not defined by small incisional window, hence able to make correlation to other neighboring structures, e.g. surface anatomy.

Able to handle the structures and make tactile inferences.

Poorly preserved skin, blood vessels.

Distorted morphology (size, shape, feel) after embalming.

Smell of preservative, formalin.

Non clinical context

\section{In the operating theatre}

Sense of anticipation and hype, heightens learning. Clinical context.

Learning of surgical anatomy.

Cleanliness and sterility

No distortion of morphology or skin texture due to embalming. Good sense of how living skin feels like. Able to understand traction versus counter traction, which is important for the surgical trainee.
Presence of blood can obscure clear observation of structures Not easily accessible. Need proper clearance from theatre sister etc. Distorted surface anatomy especially due to pathology such as hernia. Observer often positioned far from action (to maintain sterility) Small incision site or window defined by surgical drape. (inability to see big picture anatomy)

Laparoscopic approach can be disorientating to the observer. (new visual orientation needed)

Short learning time coupled with huge learning curve.

Alarms from the life support system can be distracting.

\section{In the lecture theatre}

Able to reach out to many students at one time, conversely, this can be very impersonal and lacks the warmth of small group teaching. Controlled environment with minimal distractions.
Comfortable setting but this is the very reason for students falling asleep! No clinical context although teachers can provide some background description and with pictures, videos etc.

Lack of realism (absence of cadavers and patients)

\section{CONCLUSION}

In conclusion, we hope that the Deans of medical schools and Heads of Department of Anatomy will recognize that there are now new possibilities and innovative techniques for teaching of human anatomy, and one way might harness the power of the internet so that students can understand the subject much better.

\section{REFERENCES}

[1] Boeckers, A., Fassnacht, U. and Boeckers, T.M. (2008) "Theatrum anatomicum"-A revived teaching facility in gross anatomy. Annals of Anatomy (Anatomischer Anzeiger: Official Organ of the Anatomische Gesellschaft), 190, 495-501.

[2] Sugand, K., Abrahams, P.H. and Khurana, A. (2010) The anatomy of anatomy: A review for its modernization. Anatomical Sciences Education, 3, 83-93.

[3] Ang, E.T., Sugand, K., Hartman, M., Seow, C.S., Bay, B.H. and Abrahams, P. (2012) Singapore's anatomical future: Quo vadis? Anatomical Sciences Education, 5, 234240. http://dx.doi.org/10.1002/ase.1286

[4] Drake, R.L., McBride, J.M., Lachman, N. and Pawlina, W. (2009) Medical education in the anatomical sciences: The winds of change continue to blow. Anatomical Sciences Education, 2, 253-259. http://dx.doi.org/10.1002/ase.117

[5] Findlater, G.S., Kristmundsdottir, F., Parson, S.H. and Gil- lingwater, T.H. (2012) Development of a supported selfdirected learning approach for anatomy education. Anatomical Sciences Education, 5, 114-121. http://dx.doi.org/10.1002/ase.1255

[6] Weeks, S.E., Harris, E.E. and Kinzey, W.G. (1995) Human gross anatomy: A crucial time to encourage respect and compassion in students. Clinical Anatomy, 8, 69-79. http://dx.doi.org/10.1002/ca.980080113

[7] Nicholson, H.D., Samalia, L., Gould, M., Hurst, P.R. and Woodroffe, M. (2005) A comparison of different embalming fluids on the quality of histological preservation in human cadavers. European Journal of Morphology, 42, 178-184. http://dx.doi.org/10.1080/09243860500473306

[8] Verbov, J.L. (1983) Mummified skin-An exercise in preservation. International Journal of Dermatology, 22, 46-60. http://dx.doi.org/10.1111/j.1365-4362.1983.tb02115.x

[9] Baca, V., Doubkova, A., Kachlik, D., Stingl, J. and Svatos, F. (2006) Teaching arthroscopy techniques at the Educational Center for Clinical Anatomy and Endoscopy (ECAE), Department of Anatomy, 3rd Faculty of Medicine, Charles University in Prague. Acta Chirurgiae Orthopaedicae et Traumatologiae Cechoslovaca, 73, 356-358.

[10] East, J.M., Valentine, C.S., Kanchev, E. and Blake, G.O. (2009) Sentinel lymph node biopsy for breast cancer using methylene blue dye manifests a short learning curve among experienced surgeons: A prospective tabular cumulative sum (CUSUM) analysis. BMC Surgery, 9, 2. http://dx.doi.org/10.1186/1471-2482-9-2 
[11] D’Angelo-Donovan, D.D., Dickson-Witmer, D. and Petrelli, N.J. (2012) Sentinel lymph node biopsy in breast cancer: A history and current clinical recommendations. Surgical Oncology, 21, 196-200.

http://dx.doi.org/10.1016/j.suronc.2011.12.005

[12] Lazzaro, M., et al. (2001) Sentinel node role in breast cancer surgery. European Review for Medical and Pharmacological Sciences, 5, 181-184.

[13] Szuba, A. and Rockson, S.G. (1997) Lymphedema: Anatomy, physiology and pathogenesis. Vascular Medicine, 2, 321-236.

[14] Dustmann, H.O. (1982) Diagnosis, differential diagnosis and therapy of lymphedema. Zeitschrift für Orthopädie und ihre Grenzgebiete, 120, 76-82. http://dx.doi.org/10.1055/s-2008-1051580

[15] Gregl, A. (1988) Secondary leg edema-Experimental study. Zeitschrift für Lymphologie, 12, 48-53.

[16] Ramshaw, B.J., et al. (1996) A comparison of the approaches to laparoscopic herniorrhaphy. Surgical Endoscopy, 10, 29-32. http://dx.doi.org/10.1007/s004649910006

[17] Lantis 2nd, J.C. and Schwaitzberg, S.D. (1999) Tack entrapment of the ilioinguinal nerve during laparoscopic hernia repair. Journal of Laparoendoscopic \& Advanced Surgical Techniques A, 9, 285-289. http://dx.doi.org/10.1089/lap.1999.9.285

[18] Sarikcioglu, L., Sindel, M., Akyildiz, F. and Gur, S. (2003) Anastomotic vessels in the retropubic region: Corona mortis. Folia Morphologica (Warsz), 62, 179-82.

[19] Lau, H. and Lee, F. (2003) A prospective endoscopic study of retropubic vascular anatomy in 121 patients undergoing endoscopic extraperitoneal inguinal hernioplasty. Surgical Endoscopy, 17, 1376-1379. http://dx.doi.org/10.1007/s00464-003-8800-y

[20] McClusky, D.A., et al. (2006) Groin hernia: Anatomical and surgical history. Archives of Surgery, 141, 1035-1042. http://dx.doi.org/10.1001/archsurg.141.10.1035

[21] Shimizu, S., et al. (2007) Telesurgery system with original-quality moving images over high-speed Internet: Expansion within the Asia-Pacific region. Journal of Laparoendoscopic \& Advanced Surgical Techniques A, 17, 673678. http://dx.doi.org/10.1089/lap.2007.0017

[22] Gandsas, A., et al. (2001) Laparoscopy and the internet. A surgeon survey. Surgical Endoscopy, 15, 1044-1048. http://dx.doi.org/10.1007/s004640080192

[23] Gandsas, A., et al. (2000) In-flight continuous vital signs telemetry via the Internet. Aviation, Space, and Environmental Medicine, 71, 68-71.

[24] Gandsas, A., Altrudi, R., Pleatman, M. and Silva, Y. (1998) Live interactive broadcast of laparoscopic surgery via the Internet. Surgical Endoscopy, 12, 252-255. http://dx.doi.org/10.1007/s004649900645

[25] Gandsas, A., et al. (1996) Live broadcast of surgery through the Internet. Lancet, 348, 1314. http://dx.doi.org/10.1016/S0140-6736(05)65795-9

[26] Russomano, T., et al. (2009) Tele-surgery: A new virtual tool for medical education. Studies in Health Technology and Informatics, 150, 866-870.

[27] Bockers, A., et al. (2011) Ready for the OR?-Clinical anatomy and basic surgical skills for students in their preclinical education. GMS Zeitschrift für Medizinische Ausbildung, 28, Doc45.

[28] Bockers, A., Mayer, C. and Bockers, T.M. (2013) Does learning in clinical context in anatomical sciences improve examination results, learning motivation, or learning orientation? Anatomical Sciences Education. http://dx.doi.org/10.1002/ase.1375

[29] Chapman, S.J., et al. (2013) How can we enhance undergraduate medical training in the operating room? A survey of student attitudes and opinions. Journal of Surgical Education, 70, 326-333. http://dx.doi.org/10.1016/j.jsurg.2013.01.008

[30] Mahmud, W., et al. (2011) Dissection videos do not improve anatomy examination scores. Anatomical Sciences Education, 4, 16-21. http://dx.doi.org/10.1002/ase.194

[31] Filler, T.J., Jerosch, J. and Peuker, E.T (2000) Live interdisciplinary teaching via the internet. Computer Methods and Programs in Biomedicine, 61, 157-162. http://dx.doi.org/10.1016/S0169-2607(99)00039-5

[32] Peuker, E.T., et al. (1998) Possibilities of multimedia online teaching in medical education. Zentralblatt fur $\mathrm{Gy}$ nakologie, 120, 471-473.

[33] Roser, F., et al. (2013) Live surgery in neurosurgical training courses: Essential infrastructure and technical set-up. Acta Neurochirurgica (Wien), 155, 541-545. http://dx.doi.org/10.1007/s00701-012-1578-8 